\title{
Beneficial bacteria inhibit cachexia
}

\author{
Bernard J. Varian ${ }^{1}$, Sravya Goureshetti ${ }^{1}$, Theofilos Poutahidis ${ }^{1,2}$, Jessica R. Lakritz ${ }^{1}$, \\ Tatiana Levkovich ${ }^{1}$, Caitlin Kwok ${ }^{1}$, Konstantinos Teliousis ${ }^{2}$, Yassin M. Ibrahim ${ }^{1}$, \\ Sheyla Mirabal ${ }^{1}$ and Susan E. Erdman ${ }^{1}$ \\ ${ }^{1}$ Division of Comparative Medicine, Massachusetts Institute of Technology, Cambridge, MA, USA \\ ${ }^{2}$ Laboratory of Pathology, Faculty of Veterinary Medicine, Aristotle University of Thessaloniki, Thessaloniki, Greece \\ Correspondence to: Susan E. Erdman, email: serdman@mit.edu
}

Keywords: cachexia, sarcopenia, probiotic, microbe, inflammation

Received: October 23, $2015 \quad$ Accepted: February 05, 2016

Published: February 25, 2016

\section{ABSTRACT}

Muscle wasting, known as cachexia, is a debilitating condition associated with chronic inflammation such as during cancer. Beneficial microbes have been shown to optimize systemic inflammatory tone during good health; however, interactions between microbes and host immunity in the context of cachexia are incompletely understood. Here we use mouse models to test roles for bacteria in muscle wasting syndromes. We find that feeding of a human commensal microbe, Lactobacillus reuteri, to mice is sufficient to lower systemic indices of inflammation and inhibit cachexia. Further, the microbial muscle-building phenomenon extends to normal aging as wild type animals exhibited increased growth hormone levels and up-regulation of transcription factor Forkhead Box N1 [FoxN1] associated with thymus gland retention and longevity. Interestingly, mice with a defective FoxN1 gene (athymic nude) fail to inhibit sarcopenia after $L$. reuteri therapy, indicating a FoxN1-mediated mechanism. In conclusion, symbiotic bacteria may serve to stimulate FoxN1 and thymic functions that regulate inflammation, offering possible alternatives for cachexia prevention and novel insights into roles for microbiota in mammalian ontogeny and phylogeny.

\section{INTRODUCTION}

Cachexia is a wasting syndrome characterized by adipose tissue and muscle atrophy [1-3]. Cachexia is seen in patients with cancer [1], chronic obstructive lung disease [COPD] [4], and multiple sclerosis [MS] causing serious disabilities and premature deaths [5]. Cachexia has been associated with chronic inflammation, in particular involving neutrophils, such as in patients with COPD [4]. Mouse models, such as the $A p c^{\mathrm{Min} /+}$ [ApcMIN] mutant mouse of intestinal polyposis [6], have been utilized to study cancer-associated cachexia due to uncontrolled levels of Interleukin (IL)-6 and other host inflammatory responses [7-10]. Contributions of the gut microbiome to intestinal polyposis have been examined in the ApcMIN mouse model [11-13]. In addition to numerous premalignant intestinal polyps and cachexia, ApcMIN mice also display premature thymic involution [14] linked with their early demise at a very young age.

Muscle wasting termed sarcopenia is also a feature of a natural aging process contributing to disability and death $[15,16]$. Senility-associated skeletal muscle functional impairment and atrophy have been documented in mice [17-19]. The mouse has been extensively used to study the molecular mechanisms underlying age-related sarcopenia [20]. In mammals, premature aging has been convincingly linked with ability to control inflammation via the thymus gland and generation of CD4+ lymphocytes [21-26]. These accumulated data show that increased thymic mass with proper programming of thymocytes contributes to a robust host immune system critical for sustained good health [12-19]. Thus, factors that stimulate thymic mass have vast biological significance and therapeutic potential in inflammation-associated health disorders.

Transcriptional factor Forkhead Box N1 [FoxN1] has been identified as a key factor in programming of a normal thymus and host immune system [27, 28]. Humans with defects in FoxN1 experience thymic atrophy and immune dysfunction, and also alopecia and mental depression. Mice absent FoxN1 expression, known as athymic nude mice, are without a functional thymus gland and consequently suffer premature aging and susceptibility to infections and cancer associated with immune 
dysfunction [29]. Importantly, FoxN1 therapy has been shown to stimulate thymus gland regeneration [30-32, 33] indicating potential therapeutic relevancy. Relationships between host FoxN1 expression and the microbiome have not been previously described.

Lactobacillus reuteri is a lactic-acid Gram-positive bacterium that colonizes the gastrointestinal tract of mammals and birds. The prototype Lactobacillus reuteri ATCC-PTA-6475 has been originally isolated from human's mother milk. Lactobacillus reuteri is considered a typical probiotic and was shown to ameliorate infectious and non-infectious gastrointestinal disorders in both humans and animals [34-36].

We have earlier shown that human $L$. reuteri inhibits cancer development in mice [37] and conveys various good health and fitness phenotypes including copious hair growth and counteraction of age-related changes in the testes and thyroid gland [38-41]. These studies had orally supplemented bacteria building upon the paradigm of the "hygiene hypothesis" such that inhabitants of developed countries have immune systems of reduced regulatory capacity due to too few microbes with refined diets, antibiotics and Caesarian births [42-44]. In this context, perinatal microbe exposures revealed transgenerational effects in offspring including a scurfy-like syndrome with athymia together with muscle wasting, scant hair growth, massive accumulations of neutrophils, and increased cancers of lungs and liver, in grandchildren animals [45]. Attempting to connect-the-dots, it was hypothesized that failure-to-thrive in progeny was due to insufficient thymogenesis and subsequent immune dysregulation predisposing to cancers later in life. Recognizing that epithelial transcription factor FoxN1 is pivotal in embryology and thymogenesis, here we tested whether microbe modulation of FoxN1 is a plausible unifying factor involving microbiota in host thrift and evolutionary success.

Here we evaluate microbial strategies to inhibit muscle wasting in murine models. We find greater muscle mass in mice consuming a beneficial microbe $L$. reuteri. We discover $L$. reuteri-associated muscle mass coincides with normalized blood neutrophil counts and retention of a youthful thymus gland size. Further, we discover FoxN1 is up-regulated in thymic epithelia after L. reuteri treatment commensurate with increased thymic and muscle mass. Finally, we find that nude FoxN1-deficient mice are unable to benefit from microbial treatment when compared with wild type controls. Taken together our results suggest that commensal microbiota modulate host transcriptional factors such as FoxN1 that are pivotal in mammalian fitness, survival and evolution.

\section{RESULTS}

\section{Beneficial microbe Lactobacillus reuteri inhibits cancer-associated cachexia}

Cancer-associated cachexia occurs in nearly half of all cancer patients, and is a leading cause of pre-mature death [1-3]. To first investigate whether individuals suffering cancer-associated cachexia may benefit from consuming beneficial microbes, we tested the widely utilized ApcMIN mouse model predisposed to cancer cachexia [46]. Twelve eight-week-old C57BL/6 ApcMIN mice were randomly subdivided into groups of six mice per treatment and then treated continuously until fivemonths-of-age. As expected, at the age of 5 months the ApcMIN mice we used had significantly lower body weights by comparison to their age-matched wild-type controls (ApcMIN body weight, mean $\pm \mathrm{SE}=21.48 \pm 0.65$ $v s$ wild-type body weight, mean $\pm \mathrm{SE}=42.39 \pm 2.95, p=$ 0.0014 ). For evaluation we selected the gastrocnemius that is a fast-twitch muscle and therefore more susceptible to cancer cachexia compared to other muscles [47]. By analyzing the gastrocnemius muscle of ApcMIN mice we found that feeding of $L$. reuteri in drinking water led to significantly $(p<0.05)$ larger gastrocnemius muscle masses [Figure 1A].

Upon histopathological examination of the gastrocnemius muscle, ApcMIN mice had overall appearance of muscle fibers with smaller cross-sectional area in untreated mice compared to the L. reuteri- treated ones, suggesting that $L$. reuteri protects from cancer cachexia. Microscopically, muscle fibers of untreated mice exhibited mild, occasional lesions of atrophy including vacuolated, pale and hyalinized fibers, and focal macrophage and mononuclear cell infiltration and fibrosis. These same lesions were absent from L. reuteritreated mice. Likewise, internal nuclei were readily identified in muscle fibers of untreated mice; by contrast, the presence of internal nuclei was unremarkable in the mice consuming the probiotic.

To confirm and quantify this result morphometrically, we analyzed the gastrocnemius muscle fibers of the two groups of mice. We found that ApcMIN mice fed with $L$. reuteri had a significantly larger ( $p<$ 0.0001) mean muscle fiber cross-sectional area compared to controls (Figure $1 \mathrm{~A}$ and $1 \mathrm{~B}$ ). We next used the minimal Feret's diameter of muscle fibers that generates a geometrical parameter that remains largely unaffected by miscalculations due to orientation and sectioning angles of muscle fibers [48]. For that, we then calculated the minimal Feret's diameter of cross-sectioned muscle fibers. Once again we found that the muscle fibers of L. reuteritreated mice had a significantly larger minimal Feret's diameter compared to untreated mice (Figure 1A). 
Knowing that cancer cachexia patients exhibit features of systemic inflammation [1-3], we next examined whole blood of untreated Min mice. Using circulating neutrophils as a marker for systemic inflammation, hemograms revealed that neutrophil counts were significantly elevated $(p<0.05)$ in untreated ApcMIN when compared with matched $L$. reuteri-treated mice (Figure 1C).
Earlier studies have shown that ApcMIN mice exhibit uncontrollable systemic elevations in inflammatory factors IL-6, IL-1b, and TNF-a, with these same factors also associated with cachexia in patients. However, in wild type immune-competent hosts the neutrophils and other innate immune cell-related factors are productively regulated by CD4+ T lymphocytes arising in the thymus gland [44, 49-51]. Knowing that ApcMIN mice are prone

A.

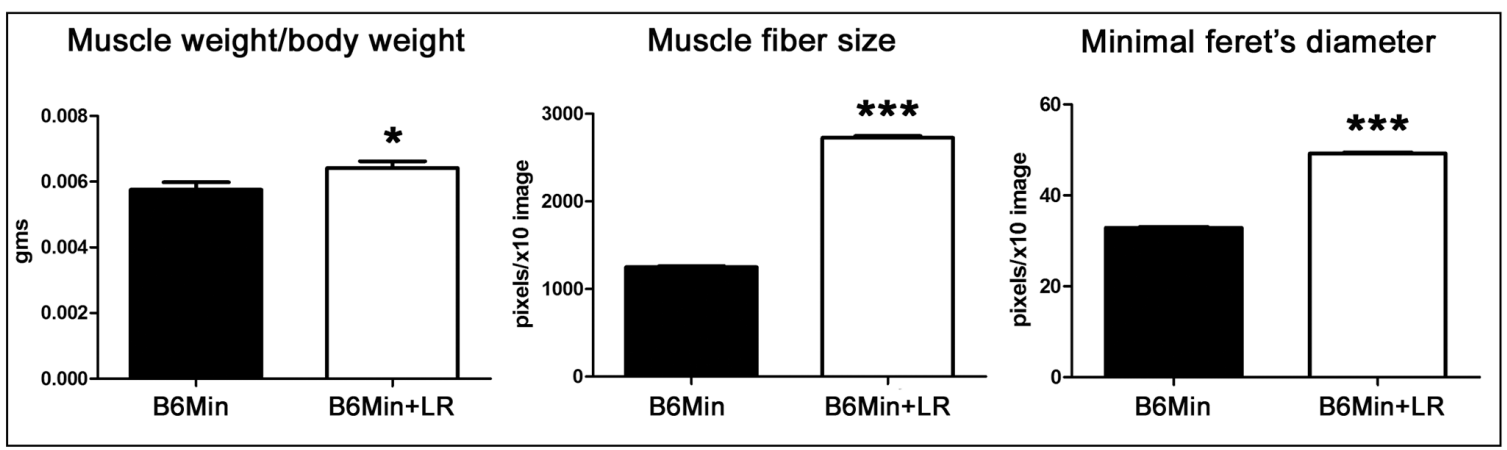

B.
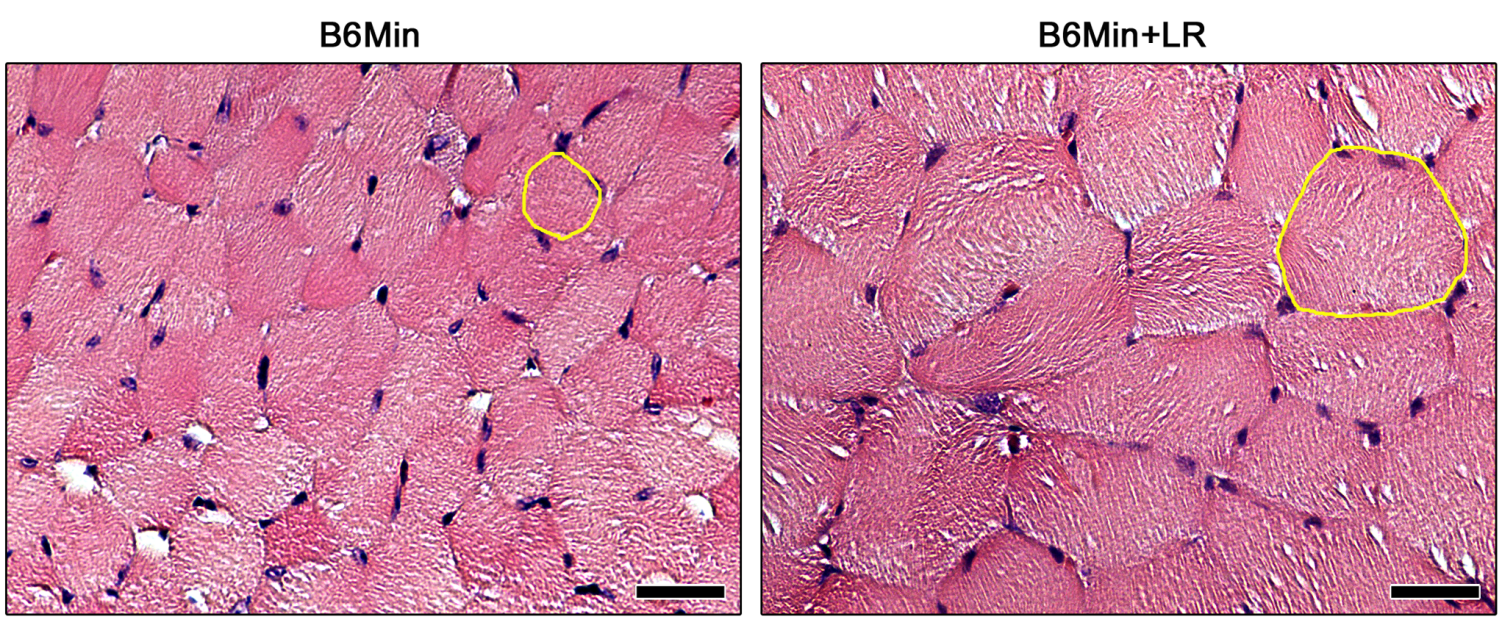

C.

D.

E.
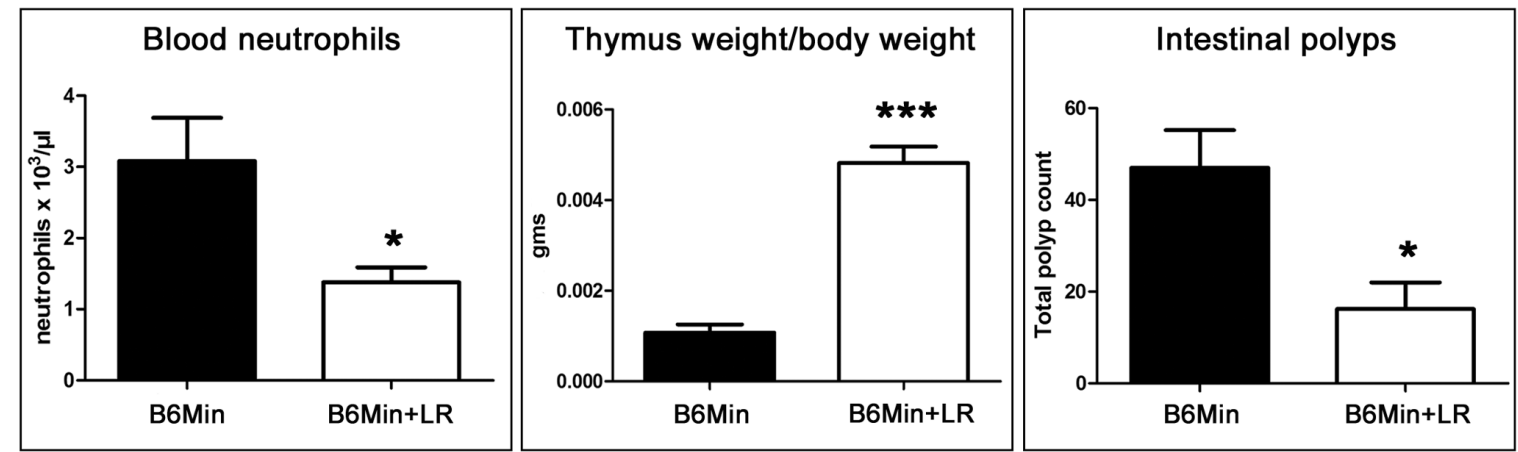

Figure 1: L. reuteri effects on gastrocnemius muscle, systemic neutrophils thymus gland and intestinal tumor burden of ApcMIN mice. A. The muscle-to-body weight ratio and critical histomomorphometrical parameters reflecting the size of muscle fibers are significantly improved with probiotic treatment $[n=6]$. B. Typical histology of gastrocnemius muscle comparing $L$. reuteri-treated mice with untreated controls $[n=6]$. The muscle fiber cross-section profiles are larger in the treated mice. Dietary L. reuteri C. downregulates blood neutrophils D. rescues thymic mass and E. counteracts intestinal polyp formation at statistically significant levels. Numbers on the y-axis of bar graphs correspond to the mean $\pm \mathrm{SEM}$ of the parameters assessed; ${ }^{*} p<0.05, * * * p<0.0001$. Hematoxylin and Eosin. Scale bars: $25 \mu \mathrm{m}$ (B) 
to premature thymic involution [14] we next evaluated whether thymus gland size was altered in animals treated orally with $L$. reuteri. We found that the thymus gland of ApcMIN mice consuming the probiotic bacterium weighed significantly more $(p<0.001)$ compared to untreated controls (Figure 2D).

While the thymus gland produces lymphocytes that regulate host inflammatory processes and inhibit cancer, it is also understood that chronic systemic inflammation associated with cancer contributes to thymic involution $[14,52]$. To address this possibility, we counted intestinal polyps in ApcMIN mice with and without feeding of probiotic. Feeding $L$ reuteri was found to not only inhibit cachexia but also reduce intestinal tumor burden $(P<0.05)$ (Figure 1E). This matches earlier studies of cachexia in ApcMIN mice [7-10], and also other recent work showing that feeding of $L$. reuteri suppresses mammary, lung and liver tumor formation in mice $[44,45,51]$. This raises the chicken-and-egg question of whether it is innate immune deficits, thymic malfunction, or tumorigenesis that initiate cachexia in ApcMIN mice. It also raises the possibility that the reduced cachexia and systemic inflammation in ApcMIN mice after L. reuteri treatment may be due to their decreased tumor burden.

L. reuteri therapy protects wild type mice from age-associated sarcopenia

In addition to diseases such as cancer, decrease of muscle mass termed 'sarcopenia' is one marker for the natural aging process. In order to test the protective effect of $L$. reuteri against muscle atrophy in a neoplasiafree experimental setting, we next used aged, 1-year-old CD1 wild-type mice. For these experiments, 20 outbred CD-1 mice were treated continuously starting at twomonths-of-age until one-year-of-age. The gastrocnemius muscle of aged CD1 mice that were consuming L. reuteri weighed significantly more $(p<0.05)$ when compared

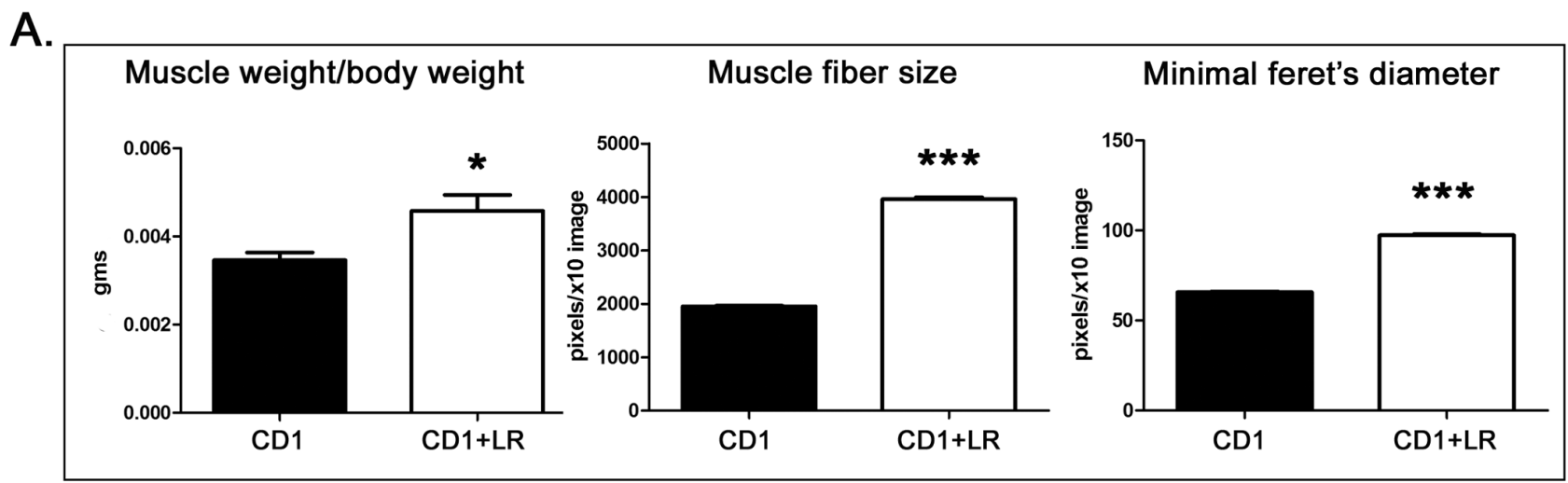

B.
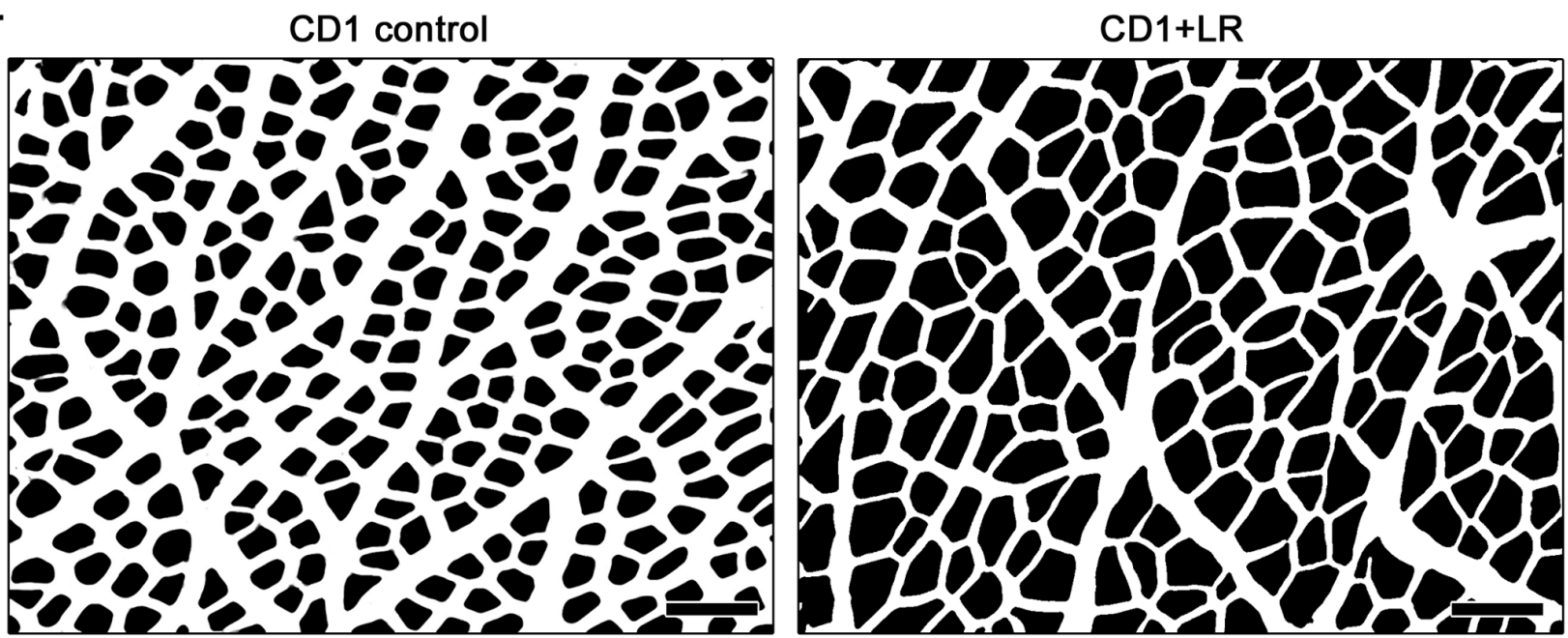

Figure 2: $L$. reuteri protects aged CD1 mice from senile sarcopenia. A. The gastrocnemius weight per body weight ratio, and the means of muscle fiber area and minimal Feret's diameter are significantly higher in probiotic-treated mice $[n=10]$ compared to their age-matched controls $[n=10]$. B. Final form of images used for morphometrical analysis of muscle fibers. The muscle fibers are analyzed as particles after image processing with ImageJ. Side-by-side comparison depicts larger muscle fiber profiles due to probiotic bacteria treatment. Numbers on the $\mathrm{y}$-axis of bar graphs correspond to the mean \pm SEM of the parameters assessed. ${ }^{*} p<0.05, * * * p<0.0001$. Original image stain: Hematoxylin and Eosin. Scale bars: $100 \mu \mathrm{m}(\mathrm{B})$ 
with untreated control mice (Figure 2A). Likewise, the histomorphometrical analysis of this muscle showed that both the muscle fiber cross-sectional area and minimal Feret's diameter were significantly larger $(p<0.0001)$ in probiotic treated mice compared to controls (Figure $2 \mathrm{~A}$ and $2 \mathrm{~B}$ ). This result suggests that $L$. reuteri protected the CD1 mice from senility-associated sarcopenia.

\section{Mice fed with $L$. reuteri have a larger thymus gland mass and increased lifespan}

Building upon the finding that cachexia-prone ApcMIN mice have a larger thymus when they consume $L$. reuteri, we tested whether a similar phenomenon was also observed in the aged CD1 mice. Indeed, the thymus of probiotic-treated CD1 mice at one year of age was larger (Figure 3A) and weighed significantly more ( $p<$ 0.001 ) than the thymus of controls (Figure 3B). Knowing that thymopoiesis and cachexia have been previously linked with growth hormone [53-56], we tested serum protein levels and found significant elevations in growth hormone (Figure 3C). Increased growth hormone levels match earlier findings with other hypothalamic-pituitary hormones after oral dosing with L reuteri [57].

The larger muscles and thymus masses suggest that L. reuteri counteracts senility-associated pathologies. To access whether this had a palpable effect on the longevity of mice we then used aged CD1 mice for survival analysis. We found that mice consuming the probiotic had a statistically significant $(p<0.01)$ survival advantage compared to the untreated controls (Figure 3D). To test whether consumption of $L$. reuteri and increased longevity coincide with a decreased systemic inflammatory tone we next tested the levels of blood neutrophils of CD1 mice. We found that CD1 mice consuming the probiotic had significantly lower $(p<0.01)$ numbers of neutrophils in their blood compared to their age-matched controls (Figure 3E). This indicated that L. reuteri act, at least in part, by restoring host immune homeostasis and lowering systemic inflammatory tone.
A.
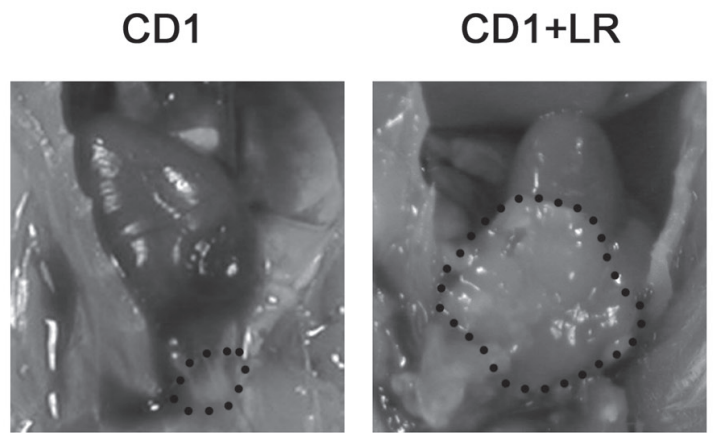

B.

Thymus weight/ body weight

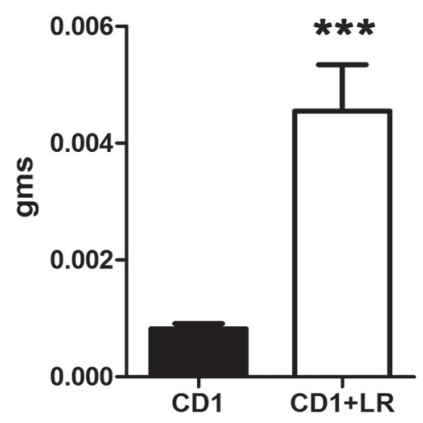

\section{Growth hormone}

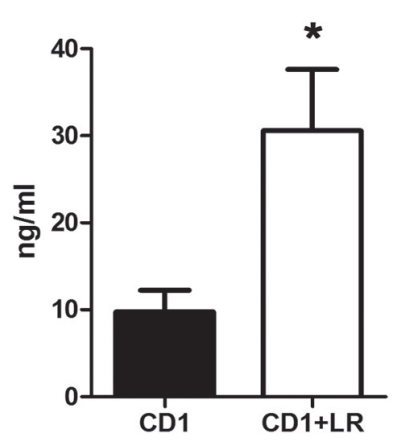

D.

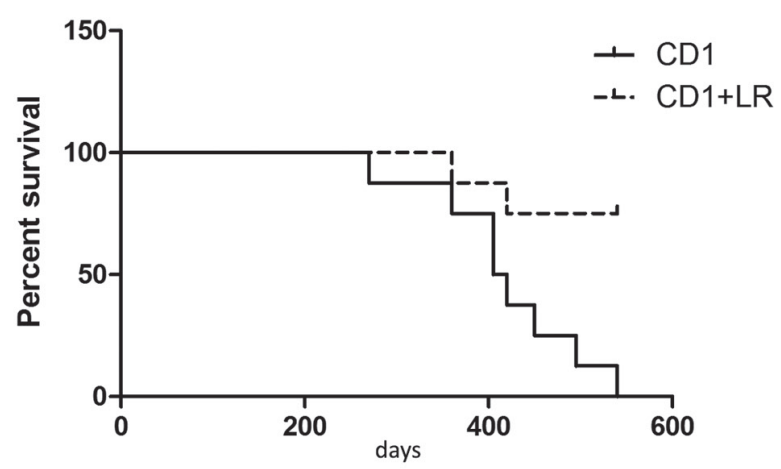

E.

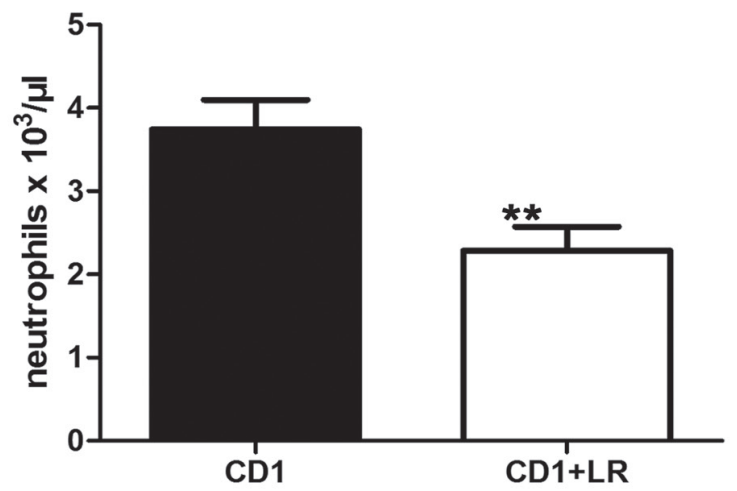

Figure 3: L. reuteri effects on thymus gland mass, longevity and systemic inflammatory tone of mice. A. Typical gross appearance of the thymus gland in L. reuteri-treated $[n=10]$ and untreated control $[n=10]$ CD1 mice. Note the larger size of thymus gland in the probiotic-treated mouse. B. The thymus gland weight/per body weight ratio is significantly increased in CD1 mice after the consumption of the probiotic bacterium. C. Survival curves of CD1 mouse cohorts $[\mathrm{n}=8$ per treatment group] depicting the longevity advantage conferred by $L$. reuteri dietary supplementation. D. The effect of $L$. reuteri in suppressing blood neutrophils is as expected in wild-type control CD1 mice. At the same time, however, this beneficial effect is lost in FoxN1-deficient mice. The y-axis depicts the mean \pm SEM of the parameters analyzed. 


\section{L. reuteri up-regulates FoxN1 expression}

Knowing that mice consuming L. reuteri have a larger thymus and that transcriptional factor Forkhead Box N1 [FoxN1] has been identified as key in thymic epitheliogenesis and programming of a normal thymus gland and host immune system $[27,28]$, we next examined FoxN1. Bredenkamp et al (2014) have recently shown shown that the inducible thymic FoxN1 expression results in robust regeneration of the involuted thymus of aged mice [32], raising the likelihood of physiological relevancy. We next, therefore, tested whether the $L$. reuteri-induced youthful thymus we observed in aged CD1 mice co-existed with elevated FoxN1 expression. For that we applied a FoxN1-specific immunohistochemical stain in thymus tissues of mice (Figure 4A). We found that the thymus of $L$. reuteri-treated mice had a significantly higher number $(p<0.0001)$ of FoxN1-positive cells by comparison with the thymus of age-matched control mice (Figure 4A and 4B). The FoxN1-positive cells were histomorphologically consistent with thymic epithelial cells and located primarily at the medulla, especially in the boundaries with the lymphocyte-rich cortex. FoxN1positive epithelial cells, however, also existed in smaller numbers within the cortical areas.

Nude mice with a defective FoxN1 gene mimic the human condition with athymia, severe immune deficiency, and hairless skin [29]. In order to test whether microbeinduced benefits require FoxN1, we next used 3-month-old wild-type and FoxN1-deficient CD1 male mice. We found that wild type mice consuming the probiotic $L$. reuteri had significantly lower $(p<0.01)$ numbers of neutrophils in their blood compared to their age-matched controls (Figure 4C); however, nude mice absent FoxN1 showed no differences in neutrophil counts after treatment with $L$. reuteri (Figure 4C).
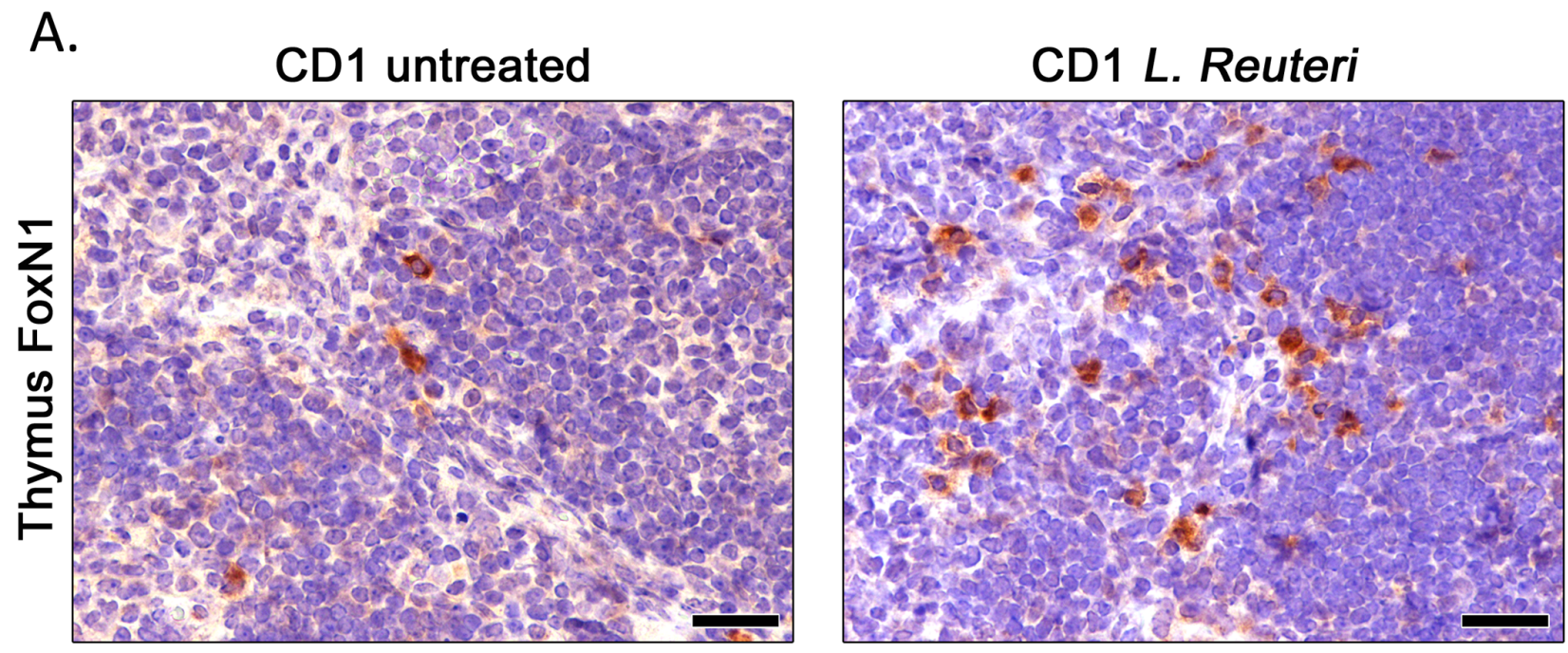

B.

C.
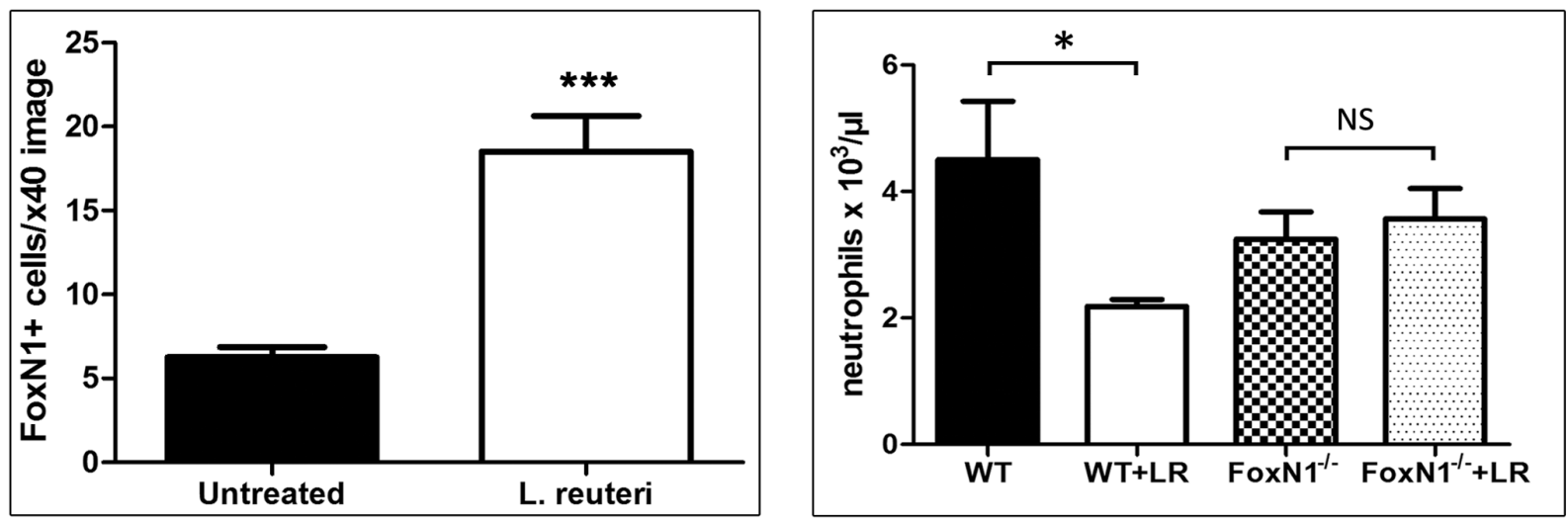

Figure 4: $L$. reuteri effects on thymus and systemic inflammatory tone are linked with FoxN1. A. FoxN1-specific immunohistochemistry on thymus gland sections of $L$. reuteri-treated $[n=10]$ and untreated mice $[n=10]$. The FoxN-1-positive thymic epithelial cell component is denser in the probiotic-treated mice. B. Results of FoxN-1-positive cell morphometric counts in thymus gland. C. The effect of L. reuteri in suppressing blood neutrophils is as expected in control CD1 mice. This beneficial effect is lost in FoxN1-deficient mice. IHC; Diaminobenzidine chromogen, Hematoxylin counterstain. Scale bars: $25 \mu \mathrm{m}$ (A). The y-axis of bar graphs depicts the mean \pm SEM of the parameters analyzed. $* p<0.05, * * * p<0.0001$. 


\section{FoxN1 is required for gut microbe-associated retention of muscle mass}

Having shown that the ability of edible $L$. reuteri in downregulating systemic neutrophils depends upon intact FoxN1, we next used the same mouse model to test whether FoxN1 is also needed for the beneficial effects of the probiotics on skeletal muscles. For these studies, ten athymic nude [CD-1 genetic background] mice and ten age-matched CD-1 controls were randomly subdivided $[n$ $=5$ mice per group] and then treated continuously starting at eight-weeks-of-age for a duration of four weeks. The gastrocnemius muscle of $L$ reuteri-treated wild-type mice was significantly $(p<0.01)$ heavier compared to untreated controls (Figure 5A). Thus, dietary supplementation with this microbe resulted in larger muscles in wild- type mice. At the same time, however, the LR effect on gastrocnemius weight was negated in recipient mice lacking the FoxN1 gene (Figure 5A). To elaborate on this result we analyzed morphometrically the gastrocnemius muscle fibers. In wild-type mice the LR treatment led to a statistically significant increase of both muscle fiber size $(p<0.01)$ and Feret's diameter $(p<0.01)$. By contrast, the same morphmetrical parameters were comparable between LR-treated and non-treated FoxN1-deficient mice (Figure $5 \mathrm{~A}$ and $5 \mathrm{~B})$.

\section{DISCUSSION}

Here we evaluate microbial strategies to inhibit muscle wasting in the context of cancer cachexia and also during normal aging. We discover in both model systems an increased muscle mass in mice consuming a beneficial

A.

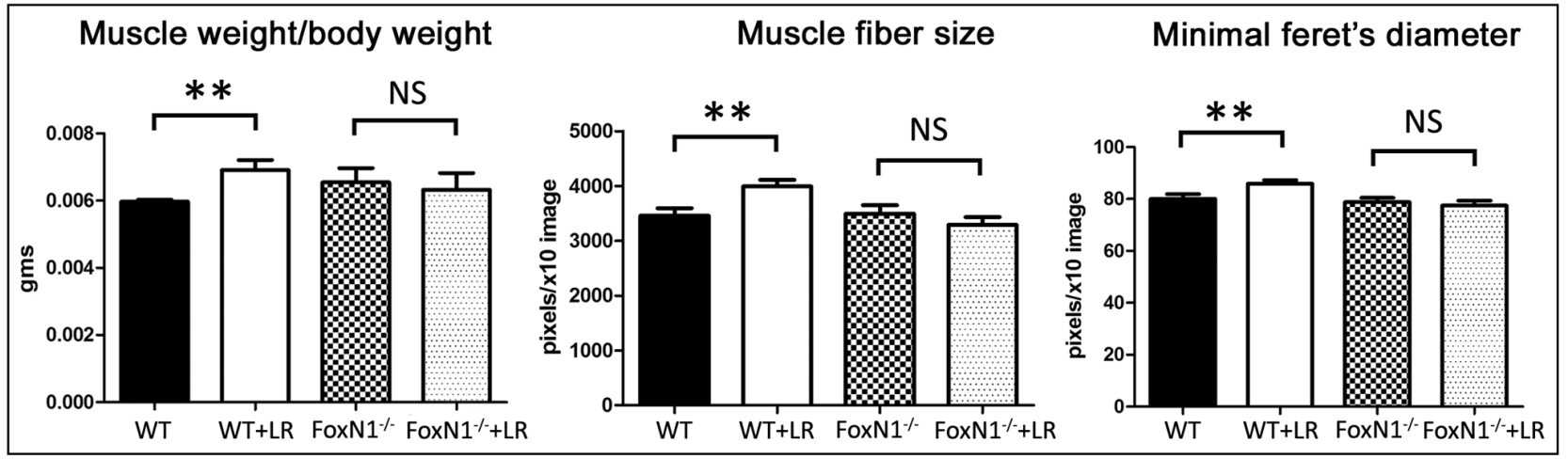

B.

FoxN1\% control

FoxN1 $\%+L R$
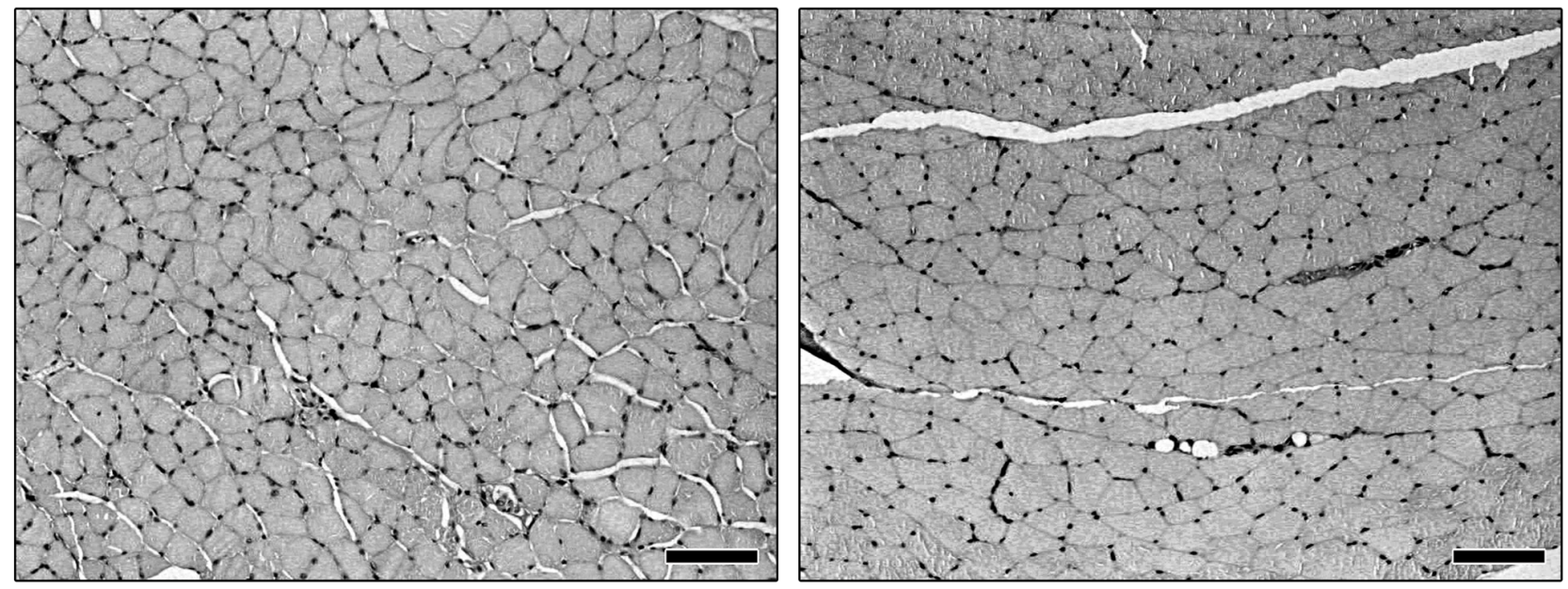

Figure 5: The beneficial effect of $\boldsymbol{L}$. reuteri on gastrocnemius muscle depends upon intact FoxN1 gene. A. While wild-type control mice $[n=5]$ present the standard improvements in the muscle-to-body weight ratio and muscle fiber size due to the probiotic treatment $[n=5]$, FoxN1-deficient mice [ $n=5$ per treatment group] fail to replicate the same phenomenon. B. The gastrocnemius muscle fibers of both $L$. reuteri-treated and untreated FoxN1-deficient mice have a comparable size. Numbers on the y-axis of bar graphs correspond to the mean \pm SEM of the parameters assessed. ${ }^{*} p<0.001$, NS: $p>0.05$. Original image stain: Hematoxylin and Eosin. Scale bars: 100 $\mu \mathrm{m}$. To increase the visibility of muscle fiber boundaries the blue channel of the original HE image was obtained using the H\&E color deconvolution plugin of ImageJ. The image product was then transformed in grayscale and uniformly enhanced using the levels command in Photoshop (B) 
human commensal microbe Lactobacillus reuteri. Along with lower risk for muscle wasting, routine feeding of $L$. reuteri in drinking water reduces blood neutrophil counts used as a surrogate marker for systemic inflammation. At the same time, mice eating $L$. reuteri also exhibit increased thymus gland size commensurate with up-regulation of Forkhead Box [Fox]N1 in thymic epithelia after $L$. reuteri therapy. Finally, in order to probe the molecular mechanism, we find that FoxN1-deficient athymic nude mice were unable to benefit from microbial treatment. Taken together our results suggest that commensal microbiota modulate host transcriptional factors such as FoxN1 that are pivotal in host fitness and survival by regulating host inflammatory tone to impart balanced immune responses (Figure 6). In this way, microbiota offer a tractable target to promote systemic homeostasis lowering risk of muscle wasting and other inflammationassociated morbidity.

A key finding is that dietary supplement with a microbe, $L$ reuteri, prevented muscle atrophy in mice. In future studies it will be interesting to examine body weight over time and functional criteria such as grip strength for improvement after intake of bacteria. In earlier studies it was shown that general food consumption was unaltered by feeding $L$ reuteri to mice [39], but that was not specifically examined here. While in the present study L. reuteri prevented senility-associated muscle atrophy in aged CD1 mice, muscle cachexia in the ApcMIN mouse model is more complicated. L. reuteri treatment in ApcMIN mice reduced the intestinal tumor burden similarly to what has been previously observed in other types of tumors $[37,45]$. This makes it difficult to assess the extent of the reduced tumor burden contribution in the prevention of cancer-associated cachexia. Further studies using $L$. reuteri treatment in different mouse models of cachexia are needed to shed light on this probiotic effect.

Cachexia has been associated with chronic systemic inflammation, in particular involving neutrophils, in health maladies such as cancer or COPD [4]. Blood neutrophil counts are one widely used surrogate marker for systemic inflammation. Several lines of evidence implicate GI tract microbiota stimulating neutrophils and other cells of innate immune cells leading to tumor formation throughout the body [11, 49, 58-64]. In order to elucidate systemic immune balance that inhibits such diseases, prior studies have focused upon reciprocal systemic relationships between neutrophils and $\mathrm{T}$ lymphocytes of adaptive immunity[37, 60, 65-70]. In the context of cancer, neutrophils have been identified in animal models and humans as an important factor in cancer initiation and development [60, 67, 71-79]. To restore and maintain good health, innate immune networks [such as those involving neutrophils] are persistently regulated by anti-inflammatory activities of CD4+ $\mathrm{T}_{\mathrm{REG}}[49,59$, 80]. According to this line of reasoning, more frequent inflammation-associated cancers arise with a weakened $\mathrm{T}_{\mathrm{REG}}$-mediated inhibitory loop with consequences of neutrophilia and elevated IL-6 heightening the risk of cachexia [51]. In prior studies, microbial phenotypes were transplantable using highly purified CD4+ lymphocyte subsets $[49,58,59,81]$. It remains to be determined which specific $\mathrm{T}$ lymphocyte subsets participate in musclerelated homeostatic processes.

During youth, the site of T lymphocyte maturation is the thymus, and the thymus gland also serves to routinely balance the activities of a normally functioning immune system during adulthood. Observation of enlarged thymus glands after eating $L$. reuteri in the present study wasn't entirely surprising. After all, the present focus upon the thymus emerged from earlier 'hygiene hypothesis'based studies, revealing repairable transgenerational phenomena of a scurfy-like athymia implicating perinatal microbial effects on the infant thymus [45]. In mammals, premature thymic involution has been convincingly linked

\title{
gut bacteria
}

\section{$\downarrow$ \\ FoxN1 $\rightarrow$ inflammatory tone}

\author{
$\downarrow \perp$ \\ musculature
}

Figure 6: Conceptual overview. Routine oral dosing of microbes inhibits muscle-wasting syndromes including cachexia and sarcopenia. Microbiota stimulate thymopoiesis and regulate systemic inflammatory tone together with muscularity by a FoxN1-dependent mechanism. 
with a wide spectrum of immune disorders resulting in failure to distinguish self from non-self [22, 23] and inability to counteract infectious diseases and cancer. Similar spontaneous thymic atrophy has been described in ApcMIN mice [14]. Thymic atrophy dovetails with observations of the 'hygiene hypothesis', such that inhabitants of developed countries have immune systems with reduced lifelong immune regulatory capacity coinciding with antibiotics and Caesarian births [42-44]. A common denominator is that impaired immune regulatory capacity leads to uncontrolled inflammatory responses and ultimately inflammation-associated cancers and other disabilities later in life [43-45]. The current observations involving cachexia match these earlier studies using dietary enrichment with beneficial bacteria [37, 39]. It's interesting the extent to which hypothalamic-pituitary hormone levels, such as growth hormone in the present study, appear to overlap in thymic health and homeostasis [53]. Oxytocin [57, 82, 83], testosterone [40], and thyroid hormone [41] were also previously found to be modulated by ingested bacteria may impact host muscle mass in these studies. Oxytocin may directly or indirectly help sustain musculature [57, 82, 83].

One important new finding is the increase in FoxN1 protein expression in thymic tissue after consuming probiotic bacteria. FoxN1 is part of the forkhead family or winged-helix transcription factors [84] that helps control production of T lymphocytes. FoxN1 is a master regulator in the thymic epithelial cell [TEC] lineage specification in that it promotes transcription of down-stream genes, which, in turn, regulate TEC differentiation. In particular, FoxN1 mainly regulates TEC patterning in the fetal stage and TEC homeostasis in the post-natal thymus [28]. Even during normal aging there is gradual decline of the thymus and immune system resulting in insufficient adaptive immunity predisposing to infections and cancer. In this way, the thymus gland has been proposed as a 'Fountain of Youth' for its key roles in immune system and consequently systemic health. By artificially stimulating FoxN1, it's been possible to rebuild the senescent thymus of aged mice[31, 32]. This raises that likelihood that targeting microbiota to modulate Wnt signaling and elevate FoxN1 will help sustain youthful thymic activities.

The FoxN1 gene and protein are also directly or indirectly important in many other developmental processes, immune system regulation, metabolism, cancer and aging [84]. Embryologically, the FoxN1rich tissue originates from the epithelium of the third pharyngeal pouch[85]. The encoded protein is proposed to also regulate differentiation of keratinocytes giving athymic nude mutant mice their hairless appearance. It is noteworthy that luxuriant fur - a feature of FoxN1 protein up-regulation - is also a prominent phenotype in mice eating L. reuteri [38]. As a result of the immune and follicular [hair production] defects, FoxN1-deficient nude mice are widely used as a model system in oncology, immunology, dermatology, and transplantation studies. Female nude mice also have underdeveloped mammary tissue and are ineffective at nursing their young [86]. In humans, FoxN1 expression is high in cerebral tissue, and brain alterations have been described in fetuses carrying the FoxN1 homozygous mutation [87]. In particular, FoxN1 is highly expressed in glial cells that make important contributions in human intelligence [88]. FoxN1 is linked with the Wnt signaling pathway providing one possible ontological and systemic mechanism linking microbes with thymogenesis [89]. Systemic growth hormone levels have also been implicated in muscle development and thymogenesis [53].

Recognizing that epithelial transcription factor FoxN1 is pivotal in mammalian thymus, hair follicles, and mammary gland development, we reasoned that environmental microbe modulation of FoxN1 is a plausible unifier of microbiota in ontogeny and phylogeny [90]. FoxN1 expression in thyroid gland tissue may help explain up-regulation of blood T4 after consumption of $L$. reuteri by mice [41]. In addition to thyroid function, FoxN1 has several key common denominators with mammalian evolution, survival and fitness: a) thymogenesis with exquisite control of self- $v s$-nonself in sustained placental pregnancy, b) robust pellage for thermal regulation, and c) mammogenesis for nutrition for placental offspring. Together these support the notion that microbe-host interactions involving FoxN1 provide the pillars for mammalian life.

In conclusion, microbiota may offer novel strategies to reduce muscle wasting and restore good systemic health. Our discovery that edible bacteria have beneficial effects on the muscle mass of mice provides elementary evidence for the presence of a gut microbiotaskeletal muscle axis in mammals. Further research of the mechanisms behind this novel axis and tests for its existence in humans may offer new alternatives for prevention of cancer-associated cachexia and other muscle wasting disorders. Commensurate up-regulation of FoxN1 in thymic epithelia by oral microbe therapy unifies bacteria and immune homeostasis. We have previously shown that sterile microbe preparations are sufficient to inhibit carcinogenesis in mice [44], and therapeutic potential of microbial fractions remains to be examined in the setting of cachexia. Taken together our results suggest that commensal microbiota modulate host resiliency via FoxN1 to regulate host inflammatory tone for effective, yet balanced, immune responses with rapid restoration of homeostasis afterwards. In this way, microbiota offer a tractable target to impart systemic homeostasis lowering risk of inflammation-associated morbidity. 


\section{MATERIALS AND METHODS}

\section{Animals}

All animals were housed in Association for the Assessment and Accreditation of Laboratory Animal Care (AAALAC)- approved facilities and maintained with approval by the Institutional Animal Care and Use Committee (IACUC) at Massachusetts Institute of Technology. Apc $c^{\mathrm{Min} /+}$ mice $[\mathrm{ApcMIN}]$ on a $\mathrm{C} 57 \mathrm{BL} / 6 \mathrm{~J}$ background were originally obtained from the Jackson labs and bred in-house to provide $A p c^{M i n /+}$ and wildtype (wt) littermates for experiments involving cancer cachexia. Outbred conventional CD-1 Swiss stock mice (Charles River; Wilmington, MA) were utilized for aging studies absent any transgenic predilections to cancer. In order to test the relevancy of FoxN1, athymic homozygous nude mice Crl:NU(NCr)-Foxn $1^{n u}$ (Charles River; Wilmington, MA) were challenged with oral microbe administration starting at the age of eight weeks. Each experiment included 5-10 animals per sex per treatment group, performed in duplicate, as described in detail below.

\section{L. reuteri administration}

In each experiment subsets of mice received in their drinking water a strain of Lactobacillus reuteri ATCCPTA-6475 cultivated as described elsewhere [57, 91]. Live organisms were supplied at a starting dosage of $3.5 \times 10^{5}$ organisms/mouse/day in drinking water with live bacterial counts in water bottles calculated as described in detail in Lakritz et al (2014) [37]. Control mice received regular drinking water. Fresh drinking water for both groups of animals was replaced twice weekly throughout the experiments.

\section{Experimental design}

\section{Experiment 1}

To probe the roles of microbiota in cancer cachexia, twelve eight-week-old C57BL/6 $A p c^{\mathrm{Min} /+}$ [ApcMIN] mice were randomly subdivided into groups of six mice per treatment and received in their drinking water Lactobacillus reuteri ATCC-PTA-6475 as described above and elsewhere $[57,91]$ continuously until five-months-ofage.

\section{Experiment 2}

To test whether oral therapy with gut microbes impacts muscle wasting during normal aging and independent of cancer, we next examined 20 outbred CD-1 mice. Experimental mice received in their drinking water $L$ reuteri ATCC-PTA-6475 as described above starting at two-months-of-age until one-year-of-age.

\section{Experiment 3}

To test whether FoxN1 is required for musclebuilding benefits of oral therapy with gut microbes, we next examined ten athymic nude CD-1 mice and ten age-matched CD-1 controls. Experimental mice were randomly subdivided and then received in their drinking water $L$ reuteri ATCC-PTA- 6475 as described above starting at eight-weeks-of-age for a duration of four weeks.

\section{Necropsy and sample collection}

Mice underwent necropsy after $\mathrm{CO}_{2}$ overdose and exsanguination. Whole blood, the gastrocnemius muscle and the thymus gland were collected for various analyses. Intestinal samples were flattened for macroscopic counts of intestinal polyps.

\section{Complete blood cell counts}

Whole blood was collected by cardiac puncture from unconscious animals upon necropsy and suspended in EDTA to prevent clotting. Automated neutrophil counts were then performed using mouse parameters in a HemaVet 950FS (Drew Scientific, Oxford CT).

\section{Serum growth hormone levels}

Whole blood was collected by cardiac puncture from unconscious animals upon necropsy to derive serum for hormone assays. Serum growth hormone levels in aged CD-1 mice were tested by radioimmunoassay (AniLytics Corp, Gaithersburg MD).

\section{Determining mass of skeletal muscle and thymus gland}

Upon necropsy, the entire mouse, plus their left gastrocnemius muscle and whole thymus gland were weighed using a ScoutPro SP202 scale [Chaus Corporation, Pinebrook NJ].

\section{Histopathology and immunohistochemistry}

For histologic evaluation, formalin-fixed gastrocnemius muscles and thymus glands were embedded in paraffin, cut at $4 \mu \mathrm{m}$, and stained with hematoxylin and eosin or immunohistochemistry. For morphometry, cross sections from the midline of the gastrocnemius muscle of six randomly selected mice per experimental group were used. Two x10 magnification images were captured from standardized areas of each 
gastrocnemius cross section. The muscle fiber area and Feret's diameter were automatically calculated in each image using the "analyze particles" command of the ImageJ image processing and analysis program (NIH, Bethesda, MD) based on a previously described methodology. A total of approximately 4000 muscle fibers were analyzed per experimental group. FoxN1-specific immunohistochemistry was performed with rabbit antiFoxN1 polyclonal antibodies (antibodies-online $\mathrm{GmbH}$, Aachen, Germany). Heat-induced antigen retrieval was performed with EDTA buffer, $\mathrm{pH}$ 8. The IHC stain and quantitative histomorphometry of IHC-positive cells in $\mathrm{x} 40$ high magnification images was done as previously described [57].

\section{Statistical analyses}

Data were compared between groups using MannWhitney $\mathrm{U}$ analysis. Statistical significance was set at $P$ $<0.05$. All analyses were performed with the Graphpad Prism version 5.0 for windows, GraphPad software, San Diego

\section{FUNDING}

This work was supported by National Institutes of Health grants R01CA108854 (to S.E.E), and U01 CA164337 (S.E.E.).

\section{CONFLICTS OF INTERESTS} interests.

There are no competing financial or commercial

\section{Author contributions}

Conceived and designed the experiments: BJV, SG, TL, JRL, SM, SEE. Performed the experiments: BJV, SG, TL, JRL, KT, SM, SEE. Analyzed the data: BJV, TP, SG, JRL, SM, CK, SEE. Contributed reagents/materials/ analysis tools: TP, SEE. Wrote the paper: BJV, TP, SEE.

\section{REFERENCES}

1. Tisdale MJ. Cachexia in cancer patients. Nat Rev Cancer. 2002; 2:862-871.

2. von Haehling S and Anker SD. Treatment of cachexia: an overview of recent developments. J Am Med Dir Assoc. 2014; 15:866-872.

3. Argiles JM, Busquets S, Stemmler B and Lopez-Soriano FJ. Cancer cachexia: understanding the molecular basis. Nat Rev Cancer. 2014; 14:754-762.

4. Schols AM and Gosker HR. The pathophysiology of cachexia in chronic obstructive pulmonary disease. Current opinion in supportive and palliative care. 2009; 3:282-287.

5. Balkwill F and Coussens LM. Cancer: an inflammatory link. Nature. 2004; 431:405-406.

6. Moser AR, Pitot HC and Dove WF. A dominant mutation that predisposes to multiple intestinal neoplasia in the mouse. Science. 1990; 247:322-324.

7. Baltgalvis KA, Berger FG, Pena MM, Davis JM, Muga SJ and Carson JA. Interleukin-6 and cachexia in ApcMin/+ mice. Am J Physiol Regul Integr Comp Physiol. 2008; 294:R393-401.

8. Naugler WE and Karin M. The wolf in sheep's clothing: the role of interleukin-6 in immunity, inflammation and cancer. Trends in molecular medicine. 2008; 14:109-119.

9. Serrano AL, Baeza-Raja B, Perdiguero E, Jardi M and Munoz-Canoves P. Interleukin-6 is an essential regulator of satellite cell-mediated skeletal muscle hypertrophy. Cell metabolism. 2008; 7:33-44.

10. Gui J, Mustachio LM, Su DM and Craig RW. Thymus Size and Age-related Thymic Involution: Early Programming, Sexual Dimorphism, Progenitors and Stroma. Aging Dis. 2012; 3:280-290.

11. Li Y, Kundu P, Seow SW, de Matos CT, Aronsson L, Chin KC, Karre K, Pettersson S and Greicius G. Gut microbiota accelerate tumor growth via c-jun and STAT3 phosphorylation in APCMin/+ mice. Carcinogenesis. 2012; 33:1231-1238.

12. Levkovich T, Poutahidis T, Cappelle K, Smith MB, Perrotta A, Alm EJ and Erdman SE. 'Hygienic' Lymphocytes Convey Increased Cancer Risk. Journal of Analytical Oncology. 2014; 3.

13. Son JS, Khair S, Pettet DW, 3rd, Ouyang N, Tian X, Zhang Y, Zhu W, Mackenzie GG, Robertson CE, Ir D, Frank $\mathrm{DN}$, Rigas B and Li E. Altered Interactions between the Gut Microbiome and Colonic Mucosa Precede Polyposis in APCMin/+ Mice. PLoS One. 2015; 10:e0127985.

14. Coletta PL, Muller AM, Jones EA, Muhl B, Holwell S, Clarke D, Meade JL, Cook GP, Hawcroft G, Ponchel F, Lam WK, MacLennan KA, Hull MA, Bonifer C and Markham AF. Lymphodepletion in the ApcMin/+ mouse model of intestinal tumorigenesis. Blood. 2004; 103:10501058.

15. Wenz T, Rossi SG, Rotundo RL, Spiegelman BM and Moraes CT. Increased muscle PGC-1alpha expression protects from sarcopenia and metabolic disease during aging. Proc Natl Acad Sci U S A. 2009; 106:20405-20410.

16. Vinciguerra M, Musaro A and Rosenthal N. Regulation of muscle atrophy in aging and disease. Adv Exp Med Biol. 2010; 694:211-233.

17. Brooks SV and Faulkner JA. Contractile properties of skeletal muscles from young, adult and aged mice. J Physiol. 1988; 404:71-82.

18. Ballak SB, Degens H, de Haan A and Jaspers RT. Aging related changes in determinants of muscle force generating capacity: a comparison of muscle aging in men and male 
rodents. Ageing Res Rev. 2014; 14:43-55.

19. Fearing CM, Melton DW, Lei X, Hancock H, Wang H, Sarwar ZU, Porter L, McHale M, McManus LM and Shireman PK. Increased Adipocyte Area in Injured Muscle With Aging and Impaired Remodeling in Female Mice. J Gerontol A Biol Sci Med Sci. 2015.

20. Romanick M, Thompson LV and Brown-Borg HM. Murine models of atrophy, cachexia, and sarcopenia in skeletal muscle. Biochim Biophys Acta. 2013; 1832:1410-1420.

21. Hori S, Nomura $T$ and Sakaguchi S. Control of regulatory $T$ cell development by the transcription factor Foxp3. Science. 2003; 299:1057-1061.

22. Wing K and Sakaguchi S. Regulatory T cells exert checks and balances on self tolerance and autoimmunity. Nat Immunol. 2010; 11:7-13.

23. Nishioka T, Shimizu J, Iida R, Yamazaki S and Sakaguchi S. CD4+CD25+Foxp3+ T cells and CD4+CD25-Foxp3+ T cells in aged mice. J Immunol. 2006; 176:6586-6593.

24. Haynes L and Swain SL. Aged-related shifts in T cell homeostasis lead to intrinsic T cell defects. Semin Immunol. 2012; 24:350-355.

25. Taub DD and Longo DL. Insights into thymic aging and regeneration. Immunol Rev. 2005; 205:72-93.

26. Ventevogel MS and Sempowski GD. Thymic rejuvenation and aging. Curr Opin Immunol. 2013; 25:516-522.

27. Guo J, Feng Y, Barnes P, Huang FF, Idell S, Su DM and Shams H. Deletion of FoxN1 in the thymic medullary epithelium reduces peripheral $\mathrm{T}$ cell responses to infection and mimics changes of aging. PLoS One. 2012; 7:e34681.

28. Romano R, Palamaro L, Fusco A, Giardino G, Gallo V, Del Vecchio L and Pignata C. FOXN1: A Master Regulator Gene of Thymic Epithelial Development Program. Front Immunol. 2013; 4:187.

29. Zhang Z, Burnley P, Coder B and Su DM. Insights on FoxN1 biological significance and usages of the "nude" mouse in studies of T-lymphopoiesis. International journal of biological sciences. 2012; 8:1156-1167.

30. Anderson G, Lane PJ and Jenkinson EJ. Generating intrathymic microenvironments to establish T-cell tolerance. Nature reviews Immunology. 2007; 7:954-963.

31. Balciunaite G, Keller MP, Balciunaite E, Piali L, Zuklys S, Mathieu YD, Gill J, Boyd R, Sussman DJ and Hollander GA. Wnt glycoproteins regulate the expression of FoxN1, the gene defective in nude mice. Nat Immunol. 2002; 3:1102-1108.

32. Bredenkamp N, Nowell CS and Blackburn CC. Regeneration of the aged thymus by a single transcription factor. Development. 2014; 141:1627-1637.

33. Zook EC, Krishack PA, Zhang S, Zeleznik-Le NJ, Firulli AB, Witte PL and Le PT. Overexpression of Foxn1 attenuates age-associated thymic involution and prevents the expansion of peripheral CD4 memory T cells. Blood. 2011; 118:5723-5731.

34. Athalye-Jape G, Rao S and Patole S. Lactobacillus reuteri
DSM 17938 as a Probiotic for Preterm Neonates: A StrainSpecific Systematic Review. Journal of parenteral and enteral nutrition. 2015.

35. Hou C, Zeng X, Yang F, Liu H and Qiao S. Study and use of the probiotic Lactobacillus reuteri in pigs: a review. Journal of animal science and biotechnology. 2015; 6:14.

36. Ojetti V, Ianiro G, Tortora A, D’Angelo G, Di Rienzo TA, Bibbo S, Migneco A and Gasbarrini A. The effect of Lactobacillus reuteri supplementation in adults with chronic functional constipation: a randomized, doubleblind, placebo-controlled trial. Journal of gastrointestinal and liver diseases. 2014; 23:387-391.

37. Lakritz JR, Poutahidis T, Levkovich T, Varian BJ, Ibrahim YM, Chatzigiagkos A, Mirabal S, Alm EJ and Erdman SE. Beneficial bacteria stimulate host immune cells to counteract dietary and genetic predisposition to mammary cancer in mice. Int J Cancer. 2014; 135:529-540.

38. Levkovich T, Poutahidis T, Smillie C, Varian BJ, Ibrahim YM, Lakritz JR, Alm EJ and Erdman SE. Probiotic bacteria induce a 'glow of health'. PLoS One. 2013; 8:e53867.

39. Poutahidis T, Kleinewietfeld M, Smillie C, Levkovich T, Perrotta A, Bhela S, Varian BJ, Ibrahim YM, Lakritz JR, Kearney SM, Chatzigiagkos A, Hafler DA, Alm EJ and Erdman SE. Microbial reprogramming inhibits Western diet-associated obesity. PLoS One. 2013; 8:e68596.

40. Poutahidis T, Springer A, Levkovich T, Qi P, Varian BJ, Lakritz JR, Ibrahim YM, Chatzigiagkos A, Alm EJ and Erdman SE. Probiotic microbes sustain youthful serum testosterone levels and testicular size in aging mice. PLoS One. 2014; 9:e84877.

41. Varian BJ, Poutahidis T, Levkovich T, Ibrahim YM, Lakritz JR, Chatzigiagkos A, Scherer-Hoock A, Alm EJ and Erdman SE. Beneficial Bacteria Stimulate Youthful Thyroid Gland Activity. J Obes Weight Loss Ther. 2014; 4.

42. Rook GA and Dalgleish A. Infection, immunoregulation, and cancer. Immunol Rev. 2011; 240:141-159.

43. Belkaid Y and Hand TW. Role of the microbiota in immunity and inflammation. Cell. 2014; 157:121-141.

44. Erdman SE and Poutahidis T. Cancer inflammation and regulatory T cells. Int J Cancer. 2010; 127:768-779.

45. Poutahidis T, Varian BJ, Levkovich T, Lakritz JR, Mirabal S, Kwok C, Ibrahim YM, Kearney SM, Chatzigiagkos A, Alm EJ and Erdman SE. Dietary microbes modulate transgenerational cancer risk. Cancer Res. 2015; 75:11971204.

46. Baltgalvis KA, Berger FG, Pena MMO, Davis JM, Muga SJ and Carson JA. Interleukin-6 and cachexia in Apc(Min/+) mice. Am J Physiol-Reg I. 2008; 294:R393-R401.

47. Baltgalvis KA, Berger FG, Pena MM, Davis JM, White JP and Carson JA. Muscle wasting and interleukin-6-induced atrogin-I expression in the cachectic Apc ( $\mathrm{Min} /+$ ) mouse. Pflugers Arch. 2009; 457:989-1001.

48. Briguet A, Courdier-Fruh I, Foster M, Meier T and Magyar JP. Histological parameters for the quantitative assessment 
of muscular dystrophy in the mdx-mouse. Neuromuscul Disord. 2004; 14:675-682.

49. Rao VP, Poutahidis T, Ge Z, Nambiar PR, Boussahmain C, Wang YY, Horwitz BH, Fox JG and Erdman SE. Innate immune inflammatory response against enteric bacteria Helicobacter hepaticus induces mammary adenocarcinoma in mice. Cancer Res. 2006; 66:7395-7400.

50. Rao VP, Poutahidis T, Ge Z, Nambiar PR, Horwitz BH, Fox JG and Erdman SE. Proinflammatory CD4+ $\mathrm{CD} 45 \mathrm{RB}$ (hi) lymphocytes promote mammary and intestinal carcinogenesis in Apc(Min/+) mice. Cancer Res. 2006; 66:57-61.

51. Erdman SE, Rao VP, Olipitz W, Taylor CL, Jackson EA, Levkovich T, Lee CW, Horwitz BH, Fox JG, Ge Z and Poutahidis $\mathrm{T}$. Unifying roles for regulatory $\mathrm{T}$ cells and inflammation in cancer. Int J Cancer. 2010; 126:1651-1665.

52. Faubion WA, De Jong YP, Molina AA, Ji H, Clarke K, Wang B, Mizoguchi E, Simpson SJ, Bhan AK and Terhorst C. Colitis is associated with thymic destruction attenuating $\mathrm{CD} 4+25+$ regulatory $\mathrm{T}$ cells in the periphery. Gastroenterology. 2004; 126:1759-1770.

53. Napolitano LA, Schmidt D, Gotway MB, Ameli N, Filbert EL, Ng MM, Clor JL, Epling L, Sinclair E, Baum PD, Li K, Killian ML, Bacchetti P and McCune JM. Growth hormone enhances thymic function in HIV-1-infected adults. J Clin Invest. 2008; 118:1085-1098.

54. Taub DD, Murphy WJ and Longo DL. Rejuvenation of the aging thymus: growth hormone-mediated and ghrelin-mediated signaling pathways. Current opinion in pharmacology. 2010; 10:408-424.

55. Leslie M. Bulking Up the Immune System: Growth hormone rejuvenates bone marrow, thymus (Immunology). Sci Aging Knowl Environ,. 2002; 4.

56. Tuffaha S, Budihardjo J, Sarhane K, Khosheim M, Song D, Broyles J, Salvatori R, Means K, Higgins J, Shores J, Hoke A, Cooney D, Lee WPE and Brandacher G. Effects of Growth Hormone Therapy on Axonal Regeneration, Muscle Atrophy, Schwann Cell Proliferation and EndOrgan Reinnervation Following Nerve Injury and Repair. Plastic and Reconstructive Surgery. 2015; 135:92-93.

57. Poutahidis T, Kearney SM, Levkovich T, Qi P, Varian BJ, Lakritz JR, Ibrahim YM, Chatzigiagkos A, Alm EJ and Erdman SE. Microbial Symbionts Accelerate Wound Healing via the Neuropeptide Hormone Oxytocin. PLoS One. 2013; 8:e78898.

58. Erdman SE, Poutahidis $\mathrm{T}$, Tomczak M, Rogers AB, Cormier K, Plank B, Horwitz BH and Fox JG. CD4+ $\mathrm{CD} 25+$ regulatory $\mathrm{T}$ lymphocytes inhibit microbially induced colon cancer in Rag2-deficient mice. Am J Pathol. 2003; 162:691-702.

59. Erdman SE, Rao VP, Poutahidis T, Ihrig MM, Ge Z, Feng Y, Tomczak M, Rogers AB, Horwitz BH and Fox JG. $\mathrm{CD} 4(+) \mathrm{CD} 25(+)$ regulatory lymphocytes require interleukin 10 to interrupt colon carcinogenesis in mice. Cancer Res.
2003; 63:6042-6050.

60. Erdman SE, Rao VP, Poutahidis T, Rogers AB, Taylor CL, Jackson EA, Ge Z, Lee CW, Schauer DB, Wogan GN, Tannenbaum SR and Fox JG. Nitric oxide and TNF\{alpha\} trigger colonic inflammation and carcinogenesis in Helicobacter hepaticus-infected, Rag2-deficient mice. Proc Natl Acad Sci U S A. 2009.

61. Nagamine CM, Rogers AB, Fox JG and Schauer DB. Helicobacter hepaticus promotes azoxymethane-initiated colon tumorigenesis in BALB/c-IL10-deficient mice. Int J Cancer. 2008; 122:832-838.

62. Arthur JC, Perez-Chanona E, Muhlbauer M, Tomkovich S, Uronis JM, Fan TJ, Campbell BJ, Abujamel T, Dogan B, Rogers AB, Rhodes JM, Stintzi A, Simpson KW, Hansen JJ, Keku TO, Fodor AA, et al. Intestinal inflammation targets cancer-inducing activity of the microbiota. Science. 2012; 338:120-123.

63. Rao VP, Poutahidis T, Fox JG and Erdman SE. Breast cancer: should gastrointestinal bacteria be on our radar screen? Cancer Res. 2007; 67:847-850.

64. Lakritz JR, Poutahidis T, Mirabal S, Varian BJ, Levkovich T, Ibrahim YM, Ward JM, Teng EC, Fisher B, Parry N, Lesage S, Alberg N, Gourishetti S, Fox JG, Ge Z and Erdman SE. Gut bacteria require neutrophils to promote mammary tumorigenesis. Oncotarget. 2015; 6:9387-9396. doi: 10.18632/oncotarget.3328.

65. Lakritz J, Poutahidis T, Mirabal S, Varian B, Levkovich T, Ibrahim Y, Ward J, Teng E, Fisher B, Parry N, Lesage S, Alberg N, Gourishetti S, Fox J, Ge Z and Erdman S. Gut bacteria require neutrophils to promote mammary tumorigenesis. Oncotarget. 2015; 6:9387-96. doi: 10.18632/ oncotarget.3328.

66. Buonocore S, Ahern PP, Uhlig HH, Ivanov, II, Littman DR, Maloy KJ and Powrie F. Innate lymphoid cells drive interleukin-23-dependent innate intestinal pathology. Nature. 2010; 464:1371-1375.

67. Rutkowski MR, Stephen TL, Svoronos N, Allegrezza MJ, Tesone AJ, Perales-Puchalt A, Brencicova E, EscovarFadul X, Nguyen JM, Cadungog MG, Zhang R, Salatino M, Tchou J, Rabinovich GA and Conejo-Garcia JR. Microbially Driven TLR5-Dependent Signaling Governs Distal Malignant Progression through Tumor-Promoting Inflammation. Cancer Cell. 2015; 27:27-40.

68. DeNardo DG and Coussens LM. Inflammation and breast cancer. Balancing immune response: crosstalk between adaptive and innate immune cells during breast cancer progression. Breast Cancer Res. 2007; 9:212.

69. Coussens LM and Pollard JW. Leukocytes in mammary development and cancer. Cold Spring Harb Perspect Biol. 2011; 3.

70. Jiang $\mathrm{X}$ and Shapiro DJ. The immune system and inflammation in breast cancer. Mol Cell Endocrinol. 2014; 382:673-682.

71. Erdman SE and Poutahidis T. Roles for inflammation and 
regulatory $\mathrm{T}$ cells in colon cancer. Toxicologic pathology. 2010; 38:76-87.

72. Karamanavi E, Angelopoulou K, Lavrentiadou S, Tsingotjidou A, Abas Z, Taitzoglou I, Vlemmas I, Erdman SE and Poutahidis T. Urokinase-Type Plasminogen Activator Deficiency Promotes Neoplasmatogenesis in the Colon of Mice. Translational Oncology. 2014; 7:174-187.

73. Doulberis M, Angelopoulou K, Kaldrymidou E, Tsingotjidou A, Abas Z, Erdman SE and Poutahidis T. Cholera-toxin suppresses carcinogenesis in a mouse model of inflammation-driven sporadic colon cancer. Carcinogenesis. 2015; 36:280-290.

74. Gregory AD and Houghton AM. Tumor-associated neutrophils: new targets for cancer therapy. Cancer Res. 2011; 71:2411-2416.

75. Lonkar P and Dedon PC. Reactive species and DNA damage in chronic inflammation: reconciling chemical mechanisms and biological fates. Int J Cancer. 2011; 128:1999-2009.

76. Grosse Y, Baan R, Straif K, Secretan B, El Ghissassi F, Bouvard V, Benbrahim-Tallaa L, Guha N, Galichet L, Cogliano V and Group WHOIAfRoCMW. A review of human carcinogens-Part A: pharmaceuticals. Lancet Oncol. 2009; 10:13-14.

77. Shacter E and Weitzman SA. Chronic inflammation and cancer. Oncology (Williston Park). 2002; 16:217-226, 229; discussion 230-212.

78. Pham CT. Neutrophil serine proteases: specific regulators of inflammation. Nature reviews Immunology. 2006; 6:541550.

79. Galdiero MR, Bonavita E, Barajon I, Garlanda C, Mantovani A and Jaillon S. Tumor associated macrophages and neutrophils in cancer. Immunobiology. 2013; 218:14021410.

80. Poutahidis T, Haigis KM, Rao VP, Nambiar PR, Taylor CL, Ge Z, Watanabe K, Davidson A, Horwitz BH, Fox JG and Erdman SE. Rapid reversal of interleukin-6-dependent epithelial invasion in a mouse model of microbially induced colon carcinoma. Carcinogenesis. 2007; 28:2614-2623.

81. Erdman SE, Rao, V.P.,, Olipitz W, Taylor, C.L.,, Jackson EJ, Levkovich T, Lee CW, Horwitz BH, Fox JG, Ge Z and Poutahidis $\mathrm{T}$. Unifying roles for regulatory $\mathrm{T}$ cells and inflammation in cancer. International Journal of Cancer. 2009; 126:1651-1665.

82. Elabd C, Cousin W, Upadhyayula P, Chen RY, Chooljian MS, Li J, Kung S, Jiang KP and Conboy IM. Oxytocin is an age-specific circulating hormone that is necessary for muscle maintenance and regeneration. Nature communications. 2014; 5:4082.

83. Geenen V, Bodart G, Henry S, Michaux H, Dardenne O, Charlet-Renard C, Martens H and Hober D. Programming of neuroendocrine self in the thymus and its defect in the development of neuroendocrine autoimmunity. Frontiers in neuroscience. 2013; 7:187.
84. Nehls M, Pfeifer D, Schorpp M, Hedrich H and Boehm T. New member of the winged-helix protein family disrupted in mouse and rat nude mutations. Nature. 1994; 372:103107.

85. Corbeaux T, Hess I, Swann JB, Kanzler B, HaasAssenbaum A and Boehm T. Thymopoiesis in mice depends on a Foxn1-positive thymic epithelial cell lineage. Proc Natl Acad Sci U S A. 2010; 107:16613-16618.

86. Hetherington CM, Hegan MA. Breeding nude (nu/nu) mice. Lab Anim. 1975; 9:19-20.

87. Amorosi S, Vigliano I, Del Giudice E, Panico L, Maruotti GM, Fusco A, Quarantelli M, Ciccone C, Ursini MV, Martinelli P and Pignata C. Brain alteration in a Nude/SCID fetus carrying FOXN1 homozygous mutation. J Neurol Sci. 2010; 298:121-123.

88. Han X, Chen M, Wang F, Windrem M, Wang S, Shanz S, Xu Q, Oberheim NA, Bekar L, Betstadt S, Silva AJ, Takano T, Goldman SA and Nedergaard M. Forebrain engraftment by human glial progenitor cells enhances synaptic plasticity and learning in adult mice. Cell Stem Cell. 2013; 12:342353.

89. Buckland J. Botulism beaten. Nature reviews Immunology. 2002; 2:628.

90. Swann JB, Weyn A, Nagakubo D, Bleul CC, Toyoda A, Happe C, Netuschil N, Hess I, Haas-Assenbaum A, Taniguchi Y, Schorpp M and Boehm T. Conversion of the thymus into a bipotent lymphoid organ by replacement of FOXN1 with its paralog, FOXN4. Cell Rep. 2014; 8:11841197.

91. Saulnier DM, Santos F, Roos S, Mistretta TA, Spinler JK, Molenaar D, Teusink B and Versalovic J. Exploring metabolic pathway reconstruction and genome-wide expression profiling in Lactobacillus reuteri to define functional probiotic features. PLoS One. 2011; 6:e18783.. 